\title{
Partogram: clinical study to assess the role of Partogram in primigravidae in labor
}

\author{
Manjulatha $\mathrm{VR}^{1}{ }^{*}$, Anitha $\mathrm{GS}^{2}$, Nirmala Shivalingaiah ${ }^{1}$
}

\author{
${ }^{1}$ Department of Obstetrics \& Gynecology, Sagar Hospital, Bangalore, India \\ ${ }^{2}$ Department of Obstetrics \& Gynecology, ESICPGIMSR, Bangalore, Karnataka, India
}

Received: 11 November 2015

Revised: 02 March 2016

Accepted: 03 March 2016

\author{
*Correspondence: \\ Dr. Manjulatha VR, \\ E-mail: manjulathavr@gmail.com
}

Copyright: () the author(s), publisher and licensee Medip Academy. This is an open-access article distributed under the terms of the Creative Commons Attribution Non-Commercial License, which permits unrestricted non-commercial use, distribution, and reproduction in any medium, provided the original work is properly cited.

\begin{abstract}
Background: Good obstetrician must always be alert to detect any sign and symptoms of abnormal labor. Prolongation of labor presents a picture of mental anguish, physical morbidity and may lead to surgical intervention. The goal of this study is to use partograph to monitor labor, initiate uterine activity that is sufficient to produce cervical change and fetal descent while avoiding uterine hyperstimulation, hypostimulation and fetal distress and provide timely surgical intervention where required.

Methods: Total of 100 primigravidae, who were booked with us till term were selected for the study and partograph recordings were commenced at $4 \mathrm{~cm}$ dilatation. Close foetal and maternal monitoring was done throughout the labour and Partogram was plotted to detect any deviation from normal course.

Results: Based on the Partogram findings the patients were grouped into "before alert line" and "between alert and action line" the mode of delivery in these patients was studied. Of the $42 \%$ of women who came into this group, $52.3 \%$ underwent cesarean delivery, $42.5 \%$ had instrumental deliveries and the remaining had vaginal deliveries.

Conclusions: This study shows that using the Partogram improves the quality of delivery care, since it permits to identify dystocia and make logical and effective interventions. It reduces unnecessary strain on mothers by reducing total duration of labour, without any increased foetal morbidity and mortality. If accepted as routine procedure, it will be suitable in all situations where the labour room remains busy and congested day and night for better and more efficient management of labour.
\end{abstract}

Keywords: Partogram, Alert line, Action line, Labour

\section{INTRODUCTION}

\section{Giving healthy baby to a healthy mother has always been the aim of obstetricians}

Life with all its vagaries is never a catwalk to anyone. This is categorically proved by many adventurous journeys one has to undertake during the course of life. The authenticity of Ian Donald' s statements "of all the journeys we ever make, the most dangerous one is the very first one we undertake through the last $10 \mathrm{~cm}$ of the birth canal", can never been doubted. To achieve this good obstetrician must always be alert to detect any sign and symptoms of abnormal labor.

Prolongation of labor presents a picture of mental anguish, physical morbidity and may lead to surgical intervention. Mother is exposed to higher risk of infection, dehydration, ketosis, unrecognized obstructed labor and loss of moral. The fetus on other hand is exposed to the dangers of infection, asphyxia, and excessive cranial molding. The risk of administrating 
anaesthesia in such women also arises. It also contributes dangers to the survival and subsequent neurological damage to child.

Thus, the obstetricians concern should centre on the duration of labor which has the great influence on both maternal and fetal morbidity. "Never let the sun set twice on the same labour" was a thought of yesterday but today 8-10 hours are considered adequate for primigravida. So was the aim of pioneers of active approach to the labor namely Driscoll, Friedman, Studd, Philpott and Castle.

The goal of this study is to use partograph to monitor labor, initiate uterine activity that is sufficient to produce cervical change and fetal descent while avoiding uterine hyperstimulation, hypostimulation and fetal distress and provide timely surgical intervention where required.

\section{Aims and objectives}

- Early detection of abnormal progress of labour.

- Prevention of prolonged labour.

- Recognize CPD long before obstructed labour.

- Assist in early decision on augmentation or termination of labour.

- Early recognition of maternal and fetal problems.

- Reducing complications due to prolonged labour in mother like $\mathrm{PPH}$, sepsis, uterine rupture and its sequele and in new born like death, hypoxia, infections etc.

\section{Review of literature}

Van Bogaert LJ did a study in South Africa, the study group included management of labor in 1595 nulliparous women in active labor, at term with a singleton pregnancy in CP. ${ }^{1}$ The standard Partogram's alert line was replaced by a customized alert line based on the lowest 10th centile of the rate of cervical dilatation of the study population.

Effect of Partogram use on outcomes for women in spontaneous labour at term was studied by Lavender $\mathrm{T}$ and others, involving 6187 women. $^{2}$ There was no evidence of any difference between Partogram and no Partogram in caesarean section, instrumental vaginal delivery or Apgar score less than seven at five minutes between the groups. When compared to a four-hour action line, women in the two-hour action line group were more likely to require oxytocin augmentation. When the three- and four-hour action line was compared, caesarean section rate was lowest in the four-hour action line group and this difference was statistically significant.

A randomized controlled trial of a Bedside Partogram in the Active Management of Primiparous Labour by Rory Windrim showed use of the Partogram in 1932 primiparous women with uncomplicated pregnancies at term. ${ }^{3}$ In this study, the use of a Partogram without a mandatory management of labour protocol had no effect on rates of $\mathrm{CS}$ or other intrapartum interventions in healthy primiparous women at term.

Role of Partogram in preventing prolonged labour was studied by Iffat Javed to determine the effect of Partogram on the frequency of prolonged labour, augmented labour, operative deliveries and whether appropriate interventions based on the Partogram will reduce maternal and perinatal complications. ${ }^{4}$ Partogram showed significant reduction in duration of labour. Results also showed significant reduction in number of augmented labour and vaginal examinations. The study concluded that by using Partogram, frequency of prolonged and augmented labour, postpartum haemorrhage, ruptured uterus, puerperal sepsis and perinatal morbidity and mortality was reduced.

A randomized controlled trial was studied by Lavender $T$, Alfirevic $\mathrm{Z}$ and the effect of different Partogram action lines on birth outcomes were studied. ${ }^{6}$

A scoring system developed by Sizer et al was used based on station and position of fetal head. ${ }^{6}$ Multiple regression analysis showed that the Partogram score and gravidity were independent predictors of duration of the second stage. The study concluded that, the second stage Partogram score at onset can predict the duration of second stage. Poor progress plotted on the Partogram is associated with non-spontaneous delivery.

The Partogram as an instrument to analyse care during labour and delivery was studied by Ivanilde Marques. Both the World Health Organization and the Brazilian Ministry of Health recommend using the Partogram to follow labour, indicating that the Partogram is an instrument that can be used as a guide when adopting interventions during labour.

The impact of delivery suite guidelines on intrapartum care in 'standard primigravida' was studied by Zarko Alfirevic. ${ }^{8}$ Written delivery suite guidelines have significant impact on the type of intrapartum care and outcome of pregnancy in low-risk women. Their availability suggests more active role of interested clinicians in the provision of intrapartum care. There is an urgent need to identify other factors that influence quality and quantity of clinical input into the care of low-risk pregnant women.

Sadler LC et al concluded that active management in nullipara associated with shorter duration of labour and high maternal satisfaction, without affecting the rate of caesarean section or maternal or new-born morbidity. ${ }^{9}$

\section{Historical review}

Partogram is a visual/graphical representation of related values or events over the course of labour. Relevant measurements might include statistics such as cervical dilation, fetal heart rate, duration of labour and vital 
signs. It is intended to provide an accurate record of the progress in labour, so that any delay or deviation from normal may be detected quickly and treated accordingly.

It was developed and extensively tested by the World Health Organization (WHO).

\section{There are different types of Partogram:}

Friedman's partogram ${ }^{10}$ devised in 1954 was based on observations of cervical dilatation and foetal station against time elapsed in hours from onset of labour. Plotting cervical dilatation against time yielded the typical sigmoid or ' $\mathrm{S}$ ' shaped curve and station against time gave rise to the hyperbolic curve. Limits of normal were defined.

Philpott and Castle introduced the concept of "ALERT" and "ACTION" lines. ${ }^{11,12}$ Alert line was drawn at a slope of 1 centimetre/hr for nulliparous women starting at zero time i.e. time of admission.

The action line was subsequently drawn two hours to the right of the alert line enabling the transfer of the patient to a specialized tertiary care centre.

World Health Organization (WHO) Partogram was designed for use in developing countries. ${ }^{13,14}$ Labour is divided into a latent phase, which should last no longer than 8hours, and an active phase starting at $3 \mathrm{~cm}$ dilatation, the rate of which should be no slower than $1 \mathrm{~cm}$ per hour. A 4-hour wait is recommended before intervention when the active phase is slow. Labor is graphed and analysis includes use of alert and action lines.

\section{Active management of labor}

The concept of active management of labour was first implemented by O'Driscoll and colleagues at the National Maternity Hospital in Dublin. ${ }^{15}$ This management system contains both organizational and medical components with physicians supervising normal spontaneous labour in nulliparous women and intervening only when labour progress slows.

\section{The goal}

O' Driscoll and colleagues published an article entitled, "Prevention of prolonged labour." He highlighted his concern that many women were experiencing difficult deliveries after prolonged labour and suffering greatly because of dehydration, confusion, repeated doses of narcotics, and infection. ${ }^{15}$ Recognizing this psychological and emotional stress, O' Driscoll developed the active management of labour principles to shorten lab or and achieve efficient uterine contractions to affect spontaneous delivery in primigravida patients.
Table 1: Organizational components.

\begin{tabular}{|ll|}
\hline Intervention & Goal \\
\hline Antenatal education & $\begin{array}{l}\text { Inform patients and } \\
\text { families regarding birthing } \\
\text { process and approach to } \\
\text { labour on admission }\end{array}$ \\
\hline $\begin{array}{l}\text { Daily physician } \\
\text { assessment } \\
\text { and rounds }\end{array}$ & $\begin{array}{l}\text { Ensure adherence to active } \\
\text { management principles, } \\
\text { assess labour progress, } \\
\text { support patient intrapartum } \\
\text { and postpartum }\end{array}$ \\
\hline $\begin{array}{l}\text { Bedside support and } \\
\text { supervision }\end{array}$ & $\begin{array}{l}\text { Provide emotional support } \\
\text { to patient and families, } \\
\text { answer questions, ensure } \\
\text { labour progression }\end{array}$ \\
\hline & $\begin{array}{l}\text { Evaluate effectiveness of } \\
\text { active management of } \\
\text { labour, evaluate } \\
\text { compliance, process } \\
\text { improvement }\end{array}$ \\
\hline
\end{tabular}

Table 2: Medical components.

\begin{tabular}{|ll|}
\hline Intervention & Goal \\
\hline Rigid inclusion criteria & $\begin{array}{l}\text { Ensure only term, } \\
\text { uncomplicated nullipara } \\
\text { are actively managed }\end{array}$ \\
\hline Strict diagnosis of labour & $\begin{array}{l}\text { Prevent admission in } \\
\text { latent labour, decrease } \\
\text { duration of labour } \\
\text { experienced in hospital, } \\
\text { possibly decrease } \\
\text { caesarean rate }\end{array}$ \\
\hline Early amniotomy & $\begin{array}{l}\text { Assess volume and } \\
\text { presence of meconium as } \\
\text { signs of fetal distress }\end{array}$ \\
\hline $\begin{array}{l}\text { Frequent assessment of } \\
\text { labour to ensure progress }\end{array}$ & $\begin{array}{l}\text { Ensure adequate progress, } \\
\text { detect first-stage dystocia }\end{array}$ \\
\hline $\begin{array}{l}\text { High-dose oxytocin for } \\
\text { dystocia (if no } \\
\text { contraindication) }\end{array}$ & $\begin{array}{l}\text { Correct dystocia by } \\
\text { achieving more efficient } \\
\text { uterine activity }\end{array}$ \\
\hline
\end{tabular}

Active management of labour is a system designed to ensure labour progression and intervene to decrease dystocia, particularly in the first stage. The benefits of shorter labour and reduced maternal and neonatal infection rates without a concomitant increase in other maternal or neonatal morbidity are proved benefits.

Overall, it seems clear that a system that includes patient education, a disciplined approach to labour diagnosis and management, indications for intervention, and peer review of outcomes has been and will continue to be of great benefit to women and children. 


\section{Partograph function ${ }^{16,17}$}

The Partogram is designed for use in all maternity settings, but has a different level of function at different levels of health care:

- In health center, the Partogram's critical function is to give early warning if labour is likely to be prolonged and to indicate that the woman should be transferred to hospital (Alert Line Function).

- In hospital settings, moving to the right of alert line serves as a warning for extra vigilance, but the action line is the critical point at which specific management decisions must be made.

In this study, WHO Partogram will be used to:

- Observe and conduct normal labour and delivery.

- In the early recognition of abnormal labour which could be due to:

$>$ Abnormal expulsive forces - uterine dysfunction.

$>$ Abnormality of fetus-malposition's inadequate molding.

$>$ Abnormality of maternal pelvis - CPD.

$>$ Cervical dystocia.

- Perform vaginal examination in labour and assess cervical dilatation accurately.

- Plot cervical dilatation accurately on a graph against time.

\section{Components of the Partograph}

- Part I: fetal condition (at top)

- Part II: progress of labour (at middle)

- Part III: maternal condition (at bottom)

- Outcome

\section{Part 1: Fetal condition}

This part of the graph is used to monitor and assess fetal condition.

- 1 - Fetal heart rate

- 2 - Membranes and liquor

- 3 - Moulding the fetal skull bones

- Caput

\section{Fetal heart rate}

Basal fetal heart rate?

- $\quad>160$ beats/mi =tachycardia

- $\quad<120$ beats $/ \mathrm{min}=$ bradycardia

- $\quad<100$ beats $/$ min = severe bradycardia
Decelerations? Yes / No

Relation to contractions?

- Early

- Variable

- Late

\section{Membranes and liquor}

- Intact Membranes

- Ruptured membranes + Clear liquor ....

- Ruptured membranes + Meconium-stained liquor .....M

- $\quad$ Ruptured membranes + Blood-stained liquor ...B

- $\quad$ Ruptured membranes + Absent liquor....A

\section{Molding the fetal skull bones}

Molding is an important indication of how adequately the pelvis can accommodate the fetal head

- $\quad$ : no moulding.

- $\quad+$ : sutures are opposed.

- $\quad++$ : sutures overlapped but reducible.

- $\quad+++$ : sutures overlapped and not reducible.

\section{Part II: Progress of labour}

- Cervical dilatation.

- Descent of the fetal head.

- Fetal position.

- Uterine contractions.

This section of the paragraph has as its central feature a graph of cervical dilatation against time.

\section{Alert line (health facility line)}

- The alert line drawn from $4 \mathrm{~cm}$ dilatation represents the rate of dilatation of $1 \mathrm{~cm} /$ hour.

- Moving to the right or the alert line means referral to hospital for extra vigilance.

\section{Action line (hospital line)}

- The action line is drawn 4 hour to the right of the alert line and parallel to it.

- This is the critical line at which specific management decisions must be made at the hospital.

\section{Cervical dilatation}

- If a woman arrives in the active phase of labour, recording of cervical dilatation starts on the alert line.

- When the active phase of labor begins, all recordings are transferred and start by pitting cervical dilatation on the alert line. 


\section{Descent of the fetal head}

- It should be assessed by abdominal examination immediately before doing a vaginal examination, using the rule of fifth to assess engagement.

- The rule of fifth means the palpable fifth of the fetal head are felt by abdominal examination to be above the level of symphysis pubis.

- When 2/5 or less of fetal head is felt above the level of symphysis pubis, this means that the head is engaged, and by vaginal examination, the lowest part of vertex has passed or is at the level of ischial spines.

- Assessing descent of the fetal head by vaginal examination.

- 0 station is at the level of the ischial spine.

\section{Uterine contractions}

- Observations of the contractions are made every hour in the latent phase and every half-hour in the active phase.

- Frequency - Assessed by number of contractions in a 10 minutes period.

- Duration - Measured in seconds from the time the contraction is first felt abdominally, to the time the contraction phases off.

- Each square represents one contraction.

Palpate number of contraction in ten minutes and duration of each contraction in seconds

- Less than 20 seconds.

- Between 20 and 40 seconds.

- More than 40 seconds.

\section{Part III: Maternal condition}

\section{Name/DOB/Gestation}

\section{Medical/Obstetrical issues}

Assess maternal condition regularly by monitoring:

- Drugs, IV fluids, and oxytocin, if labour is augmented.

- Pulse, blood pressure.

- Temperature.

- Urine volume, analysis for protein and acetone.

\section{Management of labour using the Partograph}

- Latent phase is less than 8 hours.

- Progress in active phase remains on or left of the alert line.

- Do not augment with oxytocin if latent and active phases go normally.

- Do not intervene unless complications develop.

- Artificial rupture of membranes (ARM).

- No ARM in latent phase.

- ARM at any time in active phase.

\section{Between alert and action lines}

- In health center, the women must be transferred to a hospital with facilities for caesarean section, unless the cervix is almost fully dilated.

- Observe labor progress for short period before transfer.

- Continue routine observations.

- $\quad$ ARM may be performed if membranes are still intact.

\section{At or beyond action line}

- Conduct full medical assessment.

- Consider intravenous infusion/bladder catheterization/analgesia

\section{Options}

- Deliver by caesarean section if there is fetal distress or obstructed labour.

- Augment with oxytocin by intravenous infusion if there are no contraindications.

One of the main functions of the partograph is to detect early deviation from normal progress of labour.

\section{METHODS}

Present prospective study of role of Partogram in the active management of labour in primigravidae was carried out in Sagar Hospital, Bangalore, during the period of March 2009-2011 December.

Total of 100 primigravidae who were booked with us till term were selected for the study after ruling out all factors including post-datism, medical disorders, antepartum haemorrhage, cephalopelvic disproportion, $\mathrm{Rh}$ negative patients, patients with diagnosed congenital anomalies etc.

\section{Sample size and technique}

Sample size of study population consisted of 100 patients with $\geq 37$ weeks of gestation who went into spontaneous or induced labour.

\section{Inclusion criteria}

- Booked cases who followed up till term and were willing to deliver at Sagar hospital.

- $\quad$ Primigravida with $\geq 37$ weeks of gestation who went into spontaneous or induced labour.

\section{Exclusion criteria}

- High risk pregnancies like PIH, GDM.

- Multigravida.

- Prior medical or surgical history which alters treatment in present pregnancy. 


\section{Methods of study}

On admission to labour room, for each patient, a detailed history was taken and a thorough examination was done with particular reference to the points as per proforma. The patients admitted were seen first by post graduates and then by senior staff. The decision of management was taken by the senior staff on duty. The neonatal care was attended by the paediatricians.

General examination of the patient was carried out including height, weight, pulse, blood pressure. She was examined for presence of fever, edema, pallor, and icterus. Thorough examination of cardiovascular and respiratory system was done to rule out any kind of systemic disease.

Per abdomen examination was carried out by Leopold's maneuvers. Height of uterus, fullness of flanks was noted. Lie, presentation and position of the fetus were confirmed. Amount of liquor was noted. Part of head palpable per abdomen in fifths was noted.

Duration, intensity and frequency (per ten minutes) of uterine contractions were noted.

- Position of cervix

- Consistency of cervix

- Cervical dilatation in $\mathrm{cm}$

- Effacement of cervix

- Presence of membranes

- Station of presenting part

- Position of occiput

- Detailed pelvic assessment was done to rule out obvious cephalopelvic disproportion.

Blood investigations were sent. A written consent was obtained for prostaglandin gel.

These 100 patients were studied in detail with regard to progressive cervical dilatation and advancing station in labour using Partogram. Dilatation, time graphs and descent- time graphs were constructed utilizing the relevant data.

In cases of hypotonic contractions and in order to accelerate the labor, 5 units of oxytocin was added to 500 $\mathrm{ml}$ ringer lactate and intravenous infusion given at the rate of $8 \mathrm{drops} / \mathrm{min}$ and accelerated every $30 \mathrm{~min}$ till patient got adequate contractions. Oxytocin was continued till one hour after the delivery of placenta and membranes.

\section{Monitoring of labour}

All the patients were monitored on a Partogram. A record of pulse, blood pressure and temperature was kept. Abdominal examination was carried out every $15 \mathrm{~min}$ to know about intensity, duration and frequency of uterine contraction. Descent of the head was made out by noting the head palpable in fifths per abdomen. Fetal heart rate monitored by using CTG. If FHR were $<100$ or $>160$ or in cases of hyperstimulated uterine contractions, oxytocin was discontinued.

Per vaginal examinations were repeated every 2 hours with all aseptic precautions to assess the progress of labour. Note was made about dilatation and effacement of the cervix and station of the vertex indicating descent. During second stage of labour, patients were monitored frequently. In all patients who delivered vaginally, episiotomy was given using local anaesthesia. Mediolateral episiotomy was given and sutured in layers with vicryl.

Apgar score of all babies was noted immediately at $1 \mathrm{~min}$ and 5 min after birth. Resuscitation of babies was done where necessary. All babies were weighed and examined for evidence of congenital anomalies and birth trauma.

Active management of third stage labour was done, in every patient $3 \mathrm{~cm}$ to full dilatation interval, duration of second and third stage were noted along with complication at any stage of labour. In cases of lower segment caesarian section or instrumental delivery viz. forceps or ventouse, indications and complications were also noted.

All patients were carefully watched for any evidence of postpartum haemorrhage in next 2 hours after delivery and then they were shifted to the post natal ward.

Patients were routinely examined twice daily in the post natal ward. They were looked for evidence of puerperal infection, postpartum haemorrhage, and perineal hematoma.

All patients of vaginal delivery with episiotomy were given antibiotics, haematinics and sitz bath twice daily.

All normally delivered patients were discharged on the 3rd postpartum day. Every patient was examined at the time of discharge and note was made regarding pulse, pallor, temperature, size and consistency of the uterus, breast, colour and smell of lochia, uterine tenderness and episiotomy wound. All babies were examined daily for evidence of cord sepsis jaundice, feeding, temperature, cry, activity. At discharge all mothers were advised to continue hematinics.

\section{RESULTS}

A clinical study was undertaken between March 2009 and October 2011 with 100 patients consisting of primigravida who have completed 37 weeks with cephalic presentation and the effect of active management of labour using Partogram was studied. 
Table 3: Age wise distribution of mode of delivery.

\begin{tabular}{|llll|}
\hline Age & LSCS & FTND & Instrumental \\
\hline $18-20$ & 4 & 5 & 3 \\
\hline $21-25$ & 8 & 16 & 5 \\
\hline $26-32$ & 18 & 26 & 15 \\
\hline
\end{tabular}

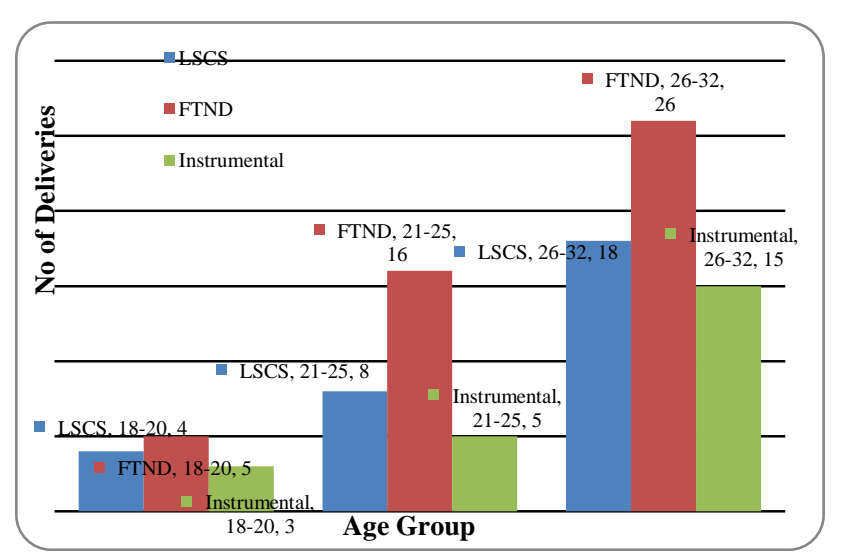

Figure 1: Age wise distribution of mode of delivery.

On grouping, the patients using age groups, maximum patients were found to belong to the 26-32 age groups. The age of the youngest patient in the study was 18 and the oldest was 32 years.

In the age group of $18-20,21-25$ and $26-32$, the percentage of FTNDs were $41.6 \%, 55.2 \%$ and $44 \%$ respectively, which was the maximum mode of delivery.

Table 4: GA wise distribution of mode of delivery.

\begin{tabular}{|llll|}
\hline GA & LSCS & FTND & Instrumental \\
\hline 37W-39W 6D & 25 & 36 & 11 \\
\hline 40W-42W & 5 & 11 & 12 \\
\hline
\end{tabular}

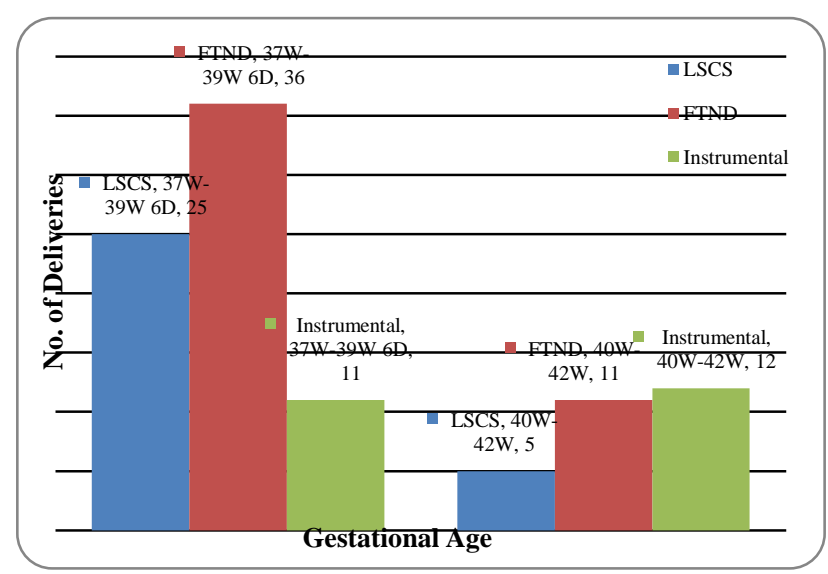

Figure 2: GA wise distribution of mode of delivery.

The patients were studied based on GA, and it was seen that $50 \%$ of women of GA $37 \mathrm{w}-39.6 \mathrm{w}$ group underwent FTND and $42.9 \%$ of women of GA $40 \mathrm{w}-42 \mathrm{w}$ had instrumental delivery.
Table 5: Height wise distribution of mode of delivery.

\begin{tabular}{|llll|}
\hline Height in CM & LSCS & FTND & Instrumental \\
\hline $145-155$ & 22 & 28 & 19 \\
\hline $156-165$ & 14 & 27 & 8 \\
\hline
\end{tabular}

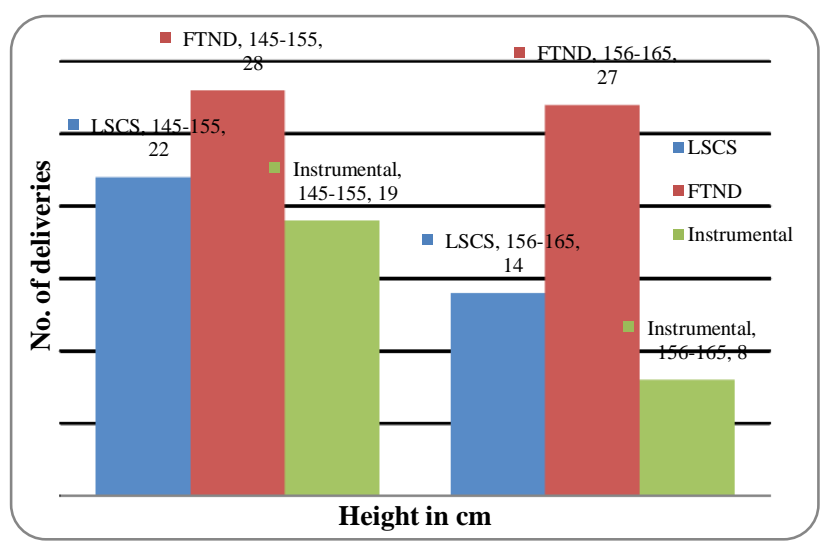

Figure 3: Height wise distribution of mode of delivery.

It is generally seen that most of tall women deliver vaginally, in this study 100 women were divided into 2 groups and women of 145-155 group had $40.6 \%$ of FTNDs and among 156-165 had $55.1 \%$ of FTNDs.

Table 6: Position of vertex and mode of delivery.

\begin{tabular}{|llll|}
\hline Position & LSCS & FTND & Instrumental \\
\hline LOA & 19 & 37 & 10 \\
\hline ROS & 11 & 10 & 13 \\
\hline
\end{tabular}

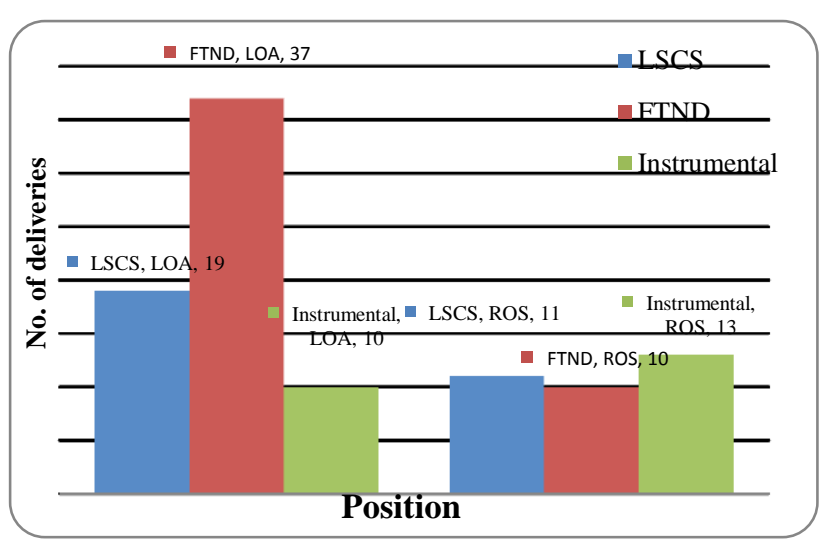

Figure 4: Position of vertex and mode of delivery.

Table 7: Contractions and mode of delivery.

\begin{tabular}{|llll|}
\hline Contractions & LSCS & FTND & Instrumental \\
\hline Mild (10-20) & 24 & 31 & 16 \\
\hline Moderate $(25-30)$ & 5 & 14 & 5 \\
\hline Strong(35-45) & 1 & 2 & 2 \\
\hline
\end{tabular}

Among 100 patients of this study, in $66 \%$ the position of vertex was LOA and in the remaining it was ROA. 
Among women with LOA, 56\% had FTND and among women with ROA, $15 \%$ had FTND (Table 6).

In this study most of the women, 71 of them were admitted with mild contractions and majority of women in this group underwent FTND. In women with mild and moderate contractions, the cases were individualised and the labour was accelerated with oxytocin where required, depending on the partograph findings (Table 7).

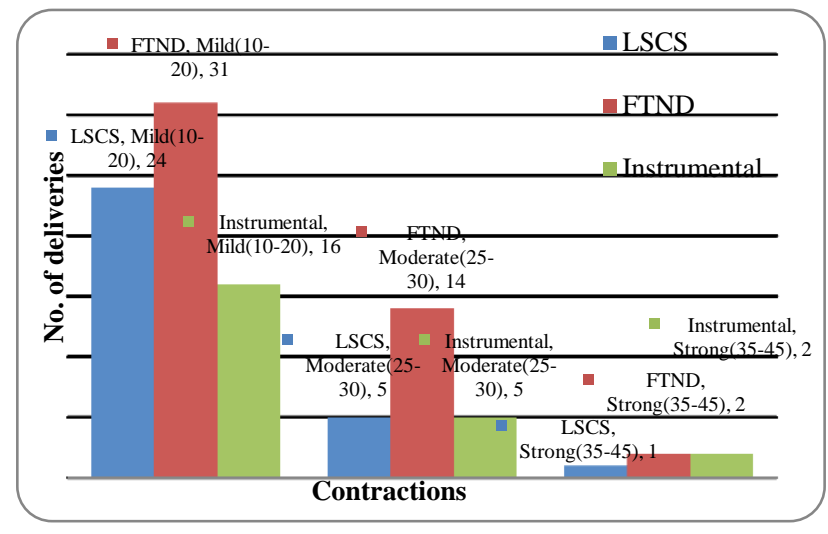

Figure 5: Contractions and mode of delivery.

Table 8: Cervical dilatation at admission and mode of delivery.

\begin{tabular}{|llll|}
\hline Dilatation in Cm & LSCS & FTND & Instrumental \\
\hline $0-2$ & 21 & 27 & 14 \\
\hline $3-4$ & 9 & 14 & 6 \\
\hline $5-6$ & 0 & 6 & 3 \\
\hline
\end{tabular}

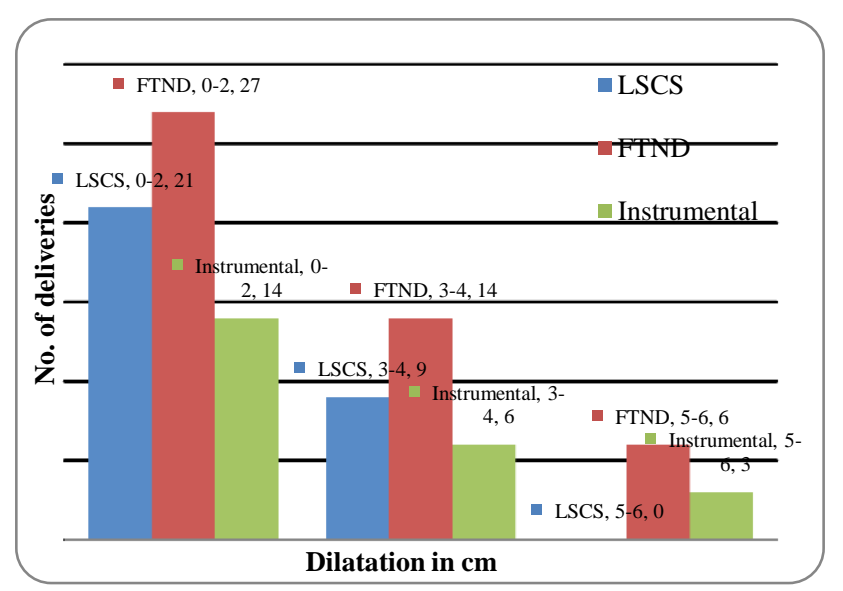

Figure 6: Cervical dilatation at admission and mode of delivery.

Table 9: Colour of liquor.

\begin{tabular}{|ll|}
\hline Liquor & No. of cases \\
\hline Clear & 86 \\
\hline Meconium & 14 \\
\hline
\end{tabular}

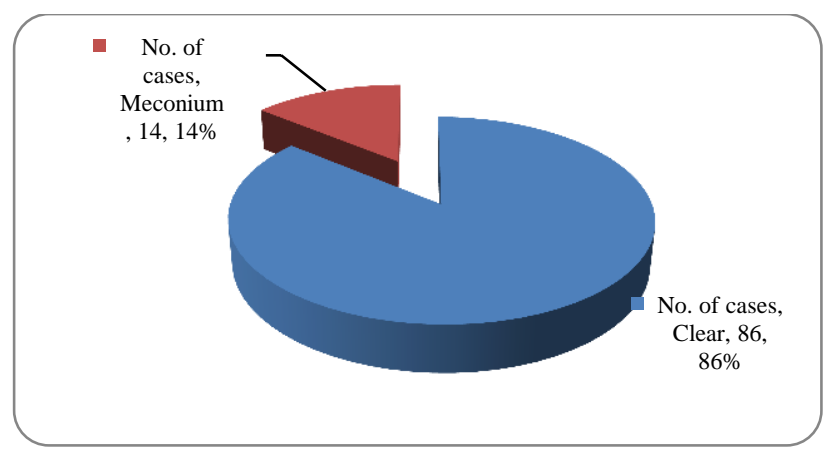

Figure 7: Colour of liquor.

Among the 100 women in this study, some had spontaneous rupture of membranes and in others ARM was done where indicated. 14 cases of meconium were reported. The fetal and maternal conditions were plotted over the Partogram, it was seen that 7 cases had prolonged tachycardia and subsequently underwent LSCS. 2 of these babies' required NICU admission and IV antibiotics for a week in view of aspiration, rest were normal.

4 cases underwent LSCS for fetal bradycardia and the babies did well. 2 among the 14 meconium cases did not show any evidence of fetal distress and hence was delivered by normal and forceps delivery.

Table 10: Station of head at admission and mode of delivery.

\begin{tabular}{|llll|}
\hline Station & LSCS & FTND & Instrumental \\
\hline-3 & 18 & 7 & 3 \\
\hline-2 & 9 & 19 & 9 \\
\hline-1 & 2 & 13 & 11 \\
\hline 0 & 1 & 8 & 0 \\
\hline
\end{tabular}

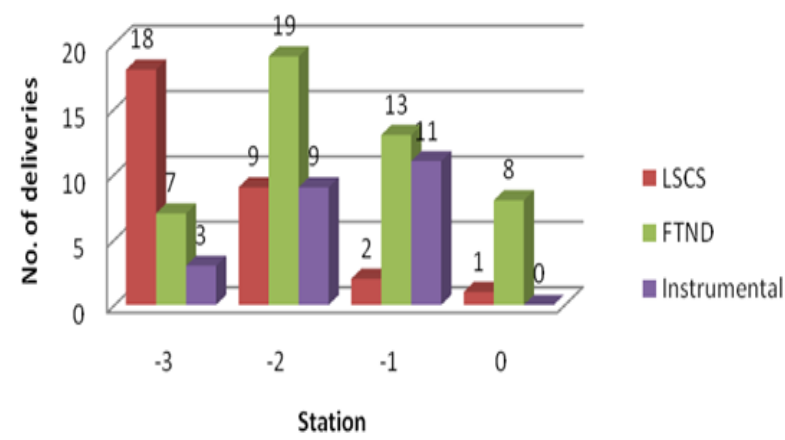

Figure 8: Station of head at admission and mode of delivery.

The table 10 shows the station of the head with respect to ischial spines at admission and the mode of delivery. The station was serially monitored over the Partogram. It was found that among the 100 women in the study, 9 cases did not have a satisfactory descent and were between alert and action line when charted on a Partogram. 4 underwent LSCS and the remaining had instrumental 
delivery. In 2 women the contractions were accelerated using oxytocin. Majority of the women were admitted with -2 station, and the minority were with 0 station.

Table 11: Method of induction and mode of delivery.

\begin{tabular}{|llll|}
\hline Induction & LSCS & FTND & Instrumental \\
\hline PG & 25 & 22 & 13 \\
\hline Spontaneous & 8 & 22 & 10 \\
\hline
\end{tabular}

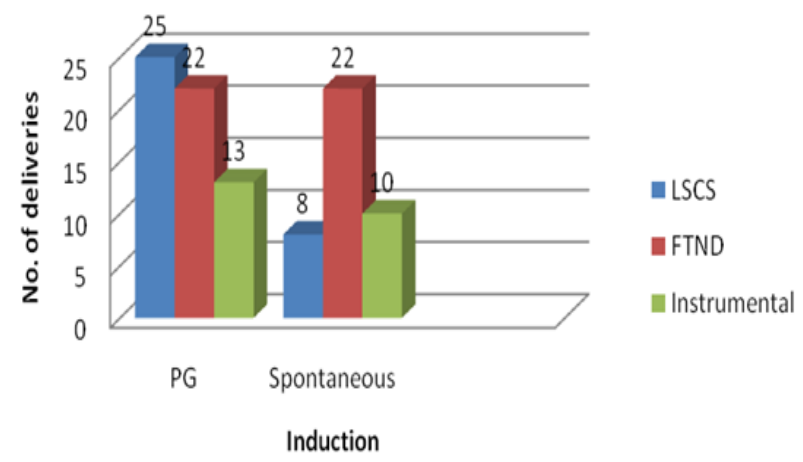

Figure 9: Method of induction and mode of delivery.

In this study, the Bishop Score assessment was done at admission and $60 \%$ of the women were induced using PGE2 gel and accordingly monitored. The majority that is $42 \%$ of women who were induced delivered by LSCS and $55 \%$ of women who were allowed to progress spontaneously delivered by FTND.

Table 12: Rate of cervical dilatation and mode of delivery.

\begin{tabular}{|llll|}
\hline $\begin{array}{l}\text { Rate of cervical } \\
\text { dilatation Cm/Hr }\end{array}$ & LSCS & FTND & Instrumental \\
\hline $0.1-1$ & 16 & 16 & 7 \\
\hline $1.1-2$ & 7 & 28 & 15 \\
\hline $2.1-2.5$ & 0 & 3 & 1 \\
\hline
\end{tabular}

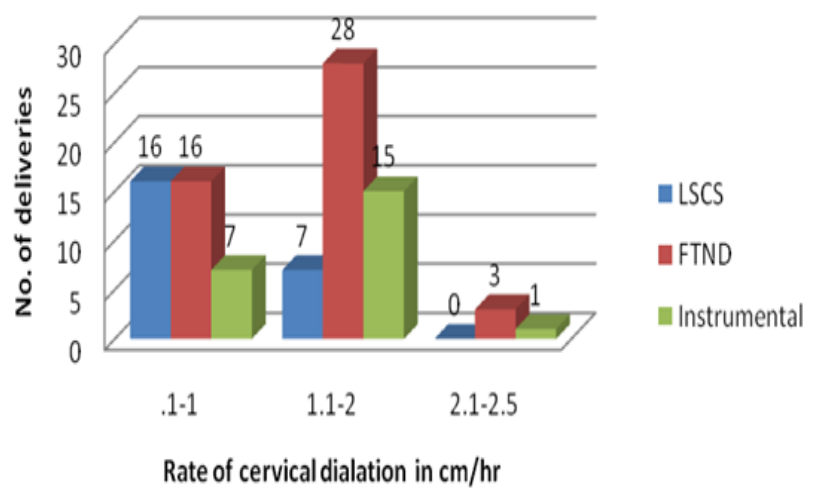

Figure 10: Rate of cervical dilatation and mode of delivery.

The 100 patients were grouped as per the rate of cervical dilatation per hour. The ideal dilatation is considered to be at least $1 \mathrm{~cm} / \mathrm{hr}$. among patients of group 1 , the majority delivered by FTND and LSCS. In group 2 and 3, majority of them delivered by FTND. Maximum number of patients i.e., 50 belonged to group 2 i.e., they dilated at the rate of $1.1-2 \mathrm{~cm}$ per hour.

Table 13: Baby weight and mode of delivery.

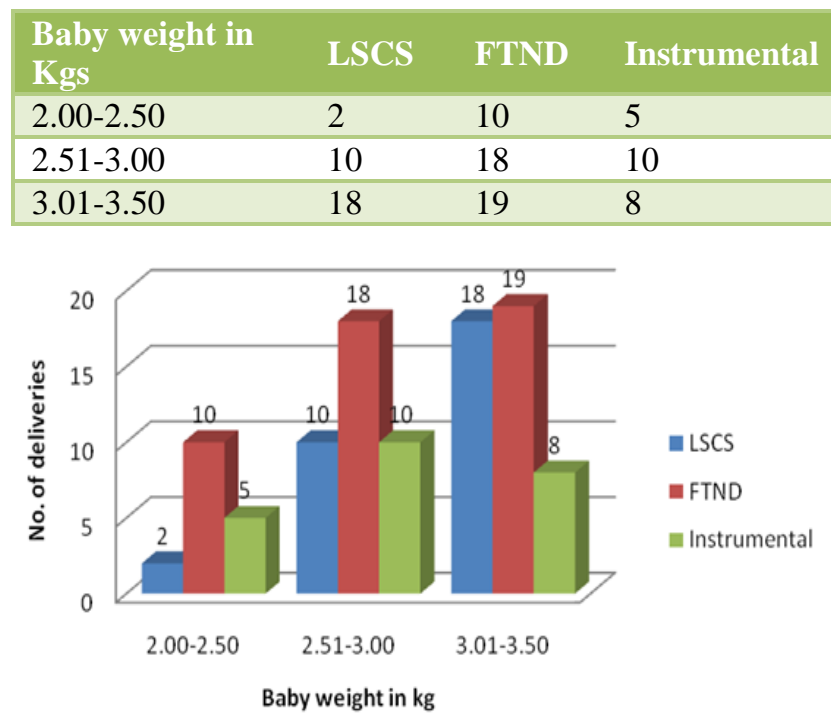

Figure 11: Baby weight and mode of delivery.

The baby's birth weight was recorded and mode of delivery compared, it was seen that majority of women delivered babies between 3.01-3.50, among the 45 of them, 19 delivered by FTND and 18 by LSCS.

Table 14: Complications.

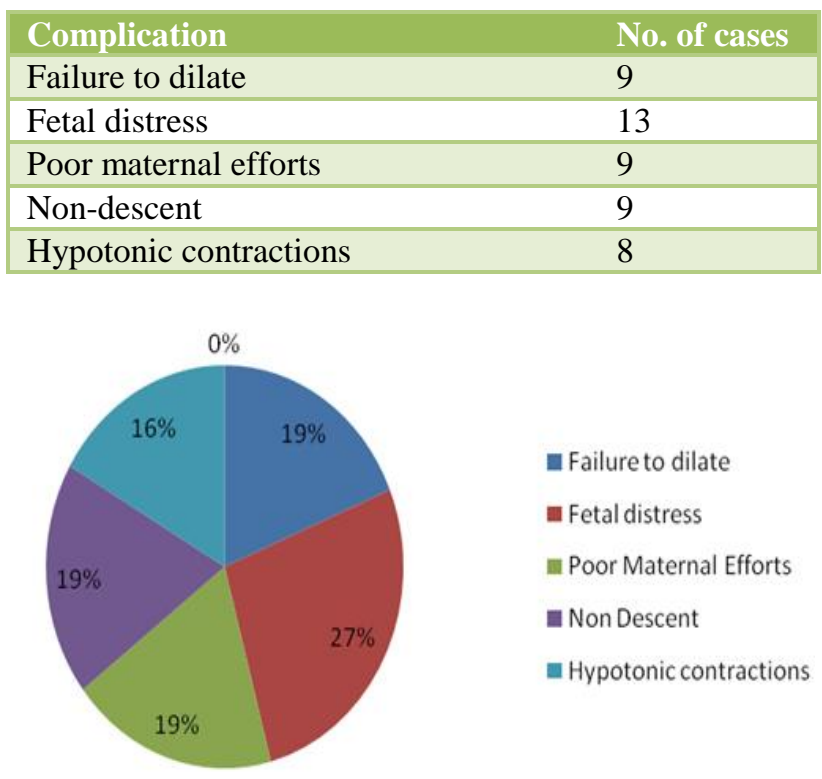

Figure 12: Complications.

The table 14 shows a list of complications, which could be detected early with the help of partogram and 
necessary interventions, were made to reduce foetal and maternal morbidity. There were 13 cases of foetal distress, majority of them underwent LSCS, and the babies responded well to minimal resuscitation, none required ventilatory support.

Table 15: Progress of labour and mode of delivery.

\begin{tabular}{|llll|}
\hline Graph & LSCS & FTND & Instrumental \\
\hline be alt line & 8 & 44 & 6 \\
\hline bt alt and act line & 22 & 3 & 17 \\
\hline
\end{tabular}

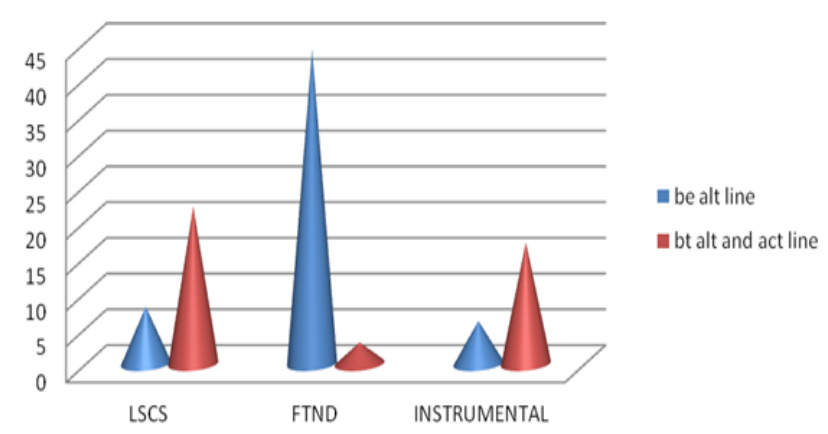

Figure 13: Progress of labour and mode of delivery.

The most important category of this study is the one mentioned below. The progress of labour was plotted on a Partogram, in those who were in between alert and action line, based on foetal and maternal status, necessary interventions like amniotomy, augmentation with oxytocin were made. The majority in this group i.e., 22 of them required LSCS, 17 had instrumental delivery and 3 of them had FTND. Partogram there by helped in intervention at the right time.

\section{DISCUSSION}

Since 1954, when Friedman first reported graphic representation of progress in labor, obstetric caregivers have used the concept of a "Partogram" to aid intrapartum care. ${ }^{10,20,21}$ Friedman's curves were based on observations of cervical dilatation and fetal station graphed against time in hours from the onset of labour. An S-shaped curve of typical cervical dilatation plotted against time was described, and normal durations of labour were defined.

Philpott developed the first formal Partogram in Zimbabwe. ${ }^{12,13}$ His aim was to promote early recognition of dystocia and referral of women from remote areas into hospitals with CS facilities. His Partogram combined the graphic details of labour progress, developed by Friedman in 1954, with Hendricks' concept of a carefully defined starting time and added information about fetal and maternal condition. ${ }^{18}$ Beazley and Kurjak modified the partogram to commence at the first vaginal examination and end at delivery. ${ }^{19}$
In England, Studd et al studied 741 consecutive spontaneous labours to identify high-risk labours that needed oxytocin stimulation. ${ }^{20,21}$ Uterine contractions were augmented if progress extended two hours past the limit indicated by the Partogram. This resulted in shorter labours, fewer instrumental deliveries and Caesarean sections, and higher neonatal Apgar scores than in those labours that were not stimulated. This study, building on the reports of Philpott and Castle was followed by increased use of the Partogram in the United Kingdom, and its use subsequently spread throughout the world. ${ }^{11,12}$

Since the 1970s, efforts have been made in many countries to reduce rising rates of CS. In addition to peer review committees and support for vaginal birth after CS (VBAC), interventions to reduce primary CS for dystocia have also been studied. The various components described by $\mathrm{O}^{\prime}$ Driscoll in his program have been studied, both collectively and separately.

In our present study 100 patients were included, of which 58 patients were before alert line, 42 were between alert and action line and none were beyond action line.

Out of the 58 before alert line 8 underwent LSCS, 6 of whom had fetal distress of which 4 had meconium stained liquor. 1 had prolonged fetal tachycardia and the other had fetal bradycardia. Due to early intervention none of the babies' required NICU care or ventilator supports.

44 of the 58 had uncomplicated vaginal delivery. 6 had instrumental deliveries, 5 due to poor maternal efforts and one due to fetal distress. 42 patients were in between alert and action lines, 22 had LSCS, 7 due to failure to dilate satisfactorily, 5 due to fetal distress, 4 for unsatisfactory descent, 6 had meconium stained amniotic fluid with prolonged variation in fetal heart rate. 17 had instrumental delivery, 2 due to fetal distress in the second stage, 4 due to poor maternal efforts during second stage, 5 due to unsatisfactory descent, 2 for meconium stained liquor in the second stage, 4 of them developed hypotonic contractions in the second stage of labour.

24 patients were started on oxytocin, among which 7 had hypotonic contractions, and in the rest in was started to accelerate labour and there by avoid undue complications.

In this study of 100 patients none of the new-borns required NICU care or ventilator support.

All the above interventions were made with respect to the Partogram plotting, which helped us to recognize undue prolongation in labour; meconium's stained liquor, fetal distress, and non-descent early and thereby reduce maternal and neonatal morbidity. 


\section{CONCLUSION}

This study shows that using the Partogram improves the quality of delivery care, since it permits to identify dystocia and make logical and effective interventions.

Using the Partogram with alert and action lines makes it easier to establish conducts to be used during labour with a normal evolution, as well as to diagnose any changes, identifying and preventing dystocia, changing intuitive conduct into a precise action.

This study shows that active management in primigravidae using Partogram has got definitive role in modern obstetrics. It reduces unnecessary strain on mothers by reducing total duration of labour, without any increased foetal morbidity and mortality. If accepted as routine procedure, it will be suitable in all situations where the labour room remains busy and congested day and night.

Thus, it seems that the value of active management of labour will be realised by most of the obstetricians and it will be accepted as a routine procedure for better and more efficient management of labour.

The only disadvantage is that it requires continuous monitoring but at the same time it gives satisfaction to labouring women as she is monitored by the same doctor there by lessening her anxiety.

\section{Recommendations}

A year plan of mortality and morbidity review meetings should be developed and strictly adhered to by all participants. The meetings should be coordinated and conducted by a senior clinician, particularly the clinical manager and be used as a continuing medical education opportunity. This should identify the causes of the perinatal deaths in the hospital and address avoidable factors that are identified.

The development and adherence to clinical guidelines within the unit need to be ensured. Decisions on when to conduct CS and assisted deliveries should be made in accordance with the guidelines.

Regular in service training of all health professionals on the importance of adequate Partogram recording is necessary.

Health care professionals should be instructed to use the Partogram for every labour case, and taught how to do this accurately.

Regular clinical audits, including record reviews need to be conducted.
Information management, including the recording, capturing, analysis and interpretation of data needs to be strengthened.

\section{Funding: Not required}

Conflict of interest: None declared

Ethical approval: The study was approved by the Institutional Ethics Committee

\section{REFERENCES}

1. Van Bogaert LJ. Revising the primigravida partogram. Arch Gynecol Obstet. 2009;279(5):643-7.

2. Lavender T, Hart A, Smyth RM. Effect of partogram use on outcomes for women in spontaneous labour at term. Cochrane Database Syst Rev. 2008;4:CD005461.

3. Windrim R, Seaward PG, Hodnett E, Akoury H, Kingdom J, Salenieks ME. A randomized controlled trial of a bedside Partogram in the active management of primiparous labour. J Obstet Gynaecol Can. 2007;29(1):27-34.

4. Javed I, Bhutta S, Shoaib T. Role of partogram in preventing prolonged labour. J Pak Med Assoc. 2007;57(8):408-11.

5. Lavender T, Alfirevic Z, Walkinshaw S. Effect of different partogram action lines on birth outcomes: a randomized controlled trial. Obstet Gynecol. 2006;108(2):295-302.

6. Sizer AR, Evans J, Bailey SM, Wiener JA. Secondstage partogram. Obstet Gynecol. 2000;96:678-83.

7. Rocha IM, de Oliveira SM, Schneck CA, Riesco ML, da Costa AS. The Partogram as an instrument to analyse care during labour and delivery. Rev Esc Enferm USP. 2009;43(4):875-83.

8. Alfirevic Z, Edwards G, Platt J. The impact of delivery suite guidelines on intrapartum care in "standard primigravida". Eur J Obstet Gynecol Reprod Biol. 2004;115(1):28-31.

9. Sadler LC, Davidson T, Mc Cowan LME. A randomised controlled trial and meta-analysis of active management of labour. Br J Obstet Gynaecol. 2000;107:909-15.

10. Friedman EA. Primigravida labour: a graphicostatistical analysis. Obstet Gynaec. 1955;6:569.

11. Philpott RH, Castle WM. Cervicographs in the management of labour - the alert line for detecting abnormal labour. Journal of Obstet and Gynaec of the British Commonwealth. 1972;79:599.

12. Philpott RH, Castle WM. Cervicographs in the management of labour- the action line for detecting abnormal labour. Journal of Obstet and Gynaec of the British Commonwealth. 1972:79.

13. WHO. World Health Organization Partogram in management of labour. The Lancet. 1994;1399-404.

14. WHO. Training modules 11. The use of the Partograph (also known as Partogram). Essential Antenatal, Perinatal and Postpartum Care. 
Copenhagen: World Health Organisation. 2002:18494.

15. O’Driscoll K, Foley M, MacDonald D. Active management of labour as an alternative to caesarean section for dystocia. Obstet Gynecol. 1984;63:48590.

16. Friedman EA. An objective approach to the diagnosis and management of abnormal labour. Bull N Y Acad Med. 1972;48:842.

17. Friedman EA. Labour: clinical evaluation and management, $2^{\text {nd }}$ ed. New York, Appleton-CenturyCrofts, 1978.
18. Hendricks $\mathrm{CH}$, Brenner WE, Kraus G. Normal cervical dilation pattern in late pregnancy and labour. Am J Obstet Gynecol. 1970;106:1065-82.

19. Beazley JM, Kurjak A. Influence of a partograph on the active management of labour. Lancet. 1972;2(7773):348-51.

20. Studd J, Clegg DR, Sanders RR, Hughes AO. Identification of high risk labours by labour nomogram. Br Med J. 1975;7:545-7.

21. Studd JWW. Partograms and normograms in the management of primigravida labour. $\mathrm{Br}$ Med $\mathrm{J}$. 1973;IV:451-5.

Cite this article as: Manjulatha VR, Anitha GS, Shivalingaiah N. Partogram: clinical study to assess the role of Partogram in primigravidae in labor. Int $\mathrm{J}$ Reprod Contracept Obstet Gynecol 2016;5:1014-25. 